\title{
Effect of heat stress on crop phenology, yield and seed quality attributes of wheat (Triticumaestivum L.)
}

\author{
MONIKAA. JOSHI, FARIDULLAH S and ATUL KUMAR \\ Division of Seed Science \& Technology, ICAR-IARI, New Delhi- 110012 \\ E-mail:monikakshat622@yahoo.com
}

\begin{abstract}
High temperature is a major determinant of wheat development and growth and causes yield loss in many regions of the world. The present study was aimed at assessing the effects of heat stress on phenologic, floral, yield and seed quality attributes of fourteen wheat genotypes under four environmental conditions; raised at two dates: November (favourable) and January (heat stress) during rabi seasons of $2012-13$ and $2013-14$. Under heat stress condition, $5-12^{\circ} \mathrm{C}$ higher temperatures were recorded at anthesis and post-anthesis stage than the normal sown. The study revealed significant differences among dates of sowing, thereby indicating sensitivity to heat stress. Among the plant morphological traits, there was a maximum reduction in plant height under heat stress condition (January sown) as compared to normal sown condition.Phenology of wheat crop was also significantly affected by higher temperature. Wheat varieties sown during the month of November took more time to reach maturity while late sown material recorded lesser crop growth duration. Among the seed yield and quality parameters, high temperature caused maximum reduction in tiller number $(70 \%)$ followed by grain yield (67.3\% reduction), 1000 -grain weight (47\% reduction) and vigour Index II (52.7\% reduction). Hence, these traits were identified as the most susceptible traits to heat stress. Heat stress also caused a reduction of 39.7 per cent for canopy temperature depression at grain filling stage. Flag leaf area, spikelet fertility and pollen fertility reduced by $33.1 \%, 22.7 \%$ and $7.7 \%$, respectively, thereby indicating that these traits were less affected due to higher temperature.Genotypes GW 366 and HD 2888 showed least heat susceptibility index (HSI)for grain yield whereas for seed quality, HD 3093 showed better tolerance compared to others.
\end{abstract}

Key words: Crop phenology, floral biology, heat stress, seed quality, wheat, yield.

Wheat is cultivated under a wide range of environment and most of the growing areas are under threat as they experience higher temperatures mainly due to global warming and climate change. Much of the increase in average global temperature is due to a projected increase in night time temperature as a result of less radiant heat loss due to increased cloudiness (Alward et al, 1999). Global circulation models have projected that the global temperature will increase by $1.4-5.8^{\circ} \mathrm{C}$ due to increase in concentrations of all greenhouse gases by the end of 21 st century (Houghton, 2001). Terminal heat stress is a problem in $40 \%$ of temperate environments, which cover 36 million ha. High temperatures, above $30^{\circ} \mathrm{C}$, affect final grain weight by reducing the duration of grain filling, dueto the suppression of current photosynthesis and by inhibition of starch synthesis in the endosperm. Heat stress during the reproductive phase can cause pollen sterility, tissue dehydration, lower $\mathrm{CO}_{2}$ assimilation and increased photorespiration. Although high temperature accelerates growth, it also reduces the phenology, which is not compensated by the increased growth rate (Zahedi and Jenner, 2003). The reproductive stage is relatively more sensitive than the vegetative stage to heat stress in many crop species. Therefore, identification and development of heat-tolerant genotypes will be most essential to meet the food requirements of growing populations in future climates. The present study was therefore undertaken to study the effects of heat stress on phenologic, floral, yield and seed quality attributes for fourteen wheat genotypes.

\section{MATERIALAND METHODS}

\section{Plant material}

The experimental material consisted of fourteen diverse wheat genotypes of bread wheat (Triticumaestivum L.) comprising different maturity groups. These were raised under timely sown (non-stress, $\mathrm{E}_{1}$ ) and late-sown (heat stress, $\mathrm{E}_{2}$ ) environments in each of the crop seasons ( $r a b i$ 
2012-13 and 2013-14) at the farm of Division of Seed Science and Technology, ICAR-IARI, New Delhi, thereby making a total of four environments. The experimental field was ploughed and leveled and then divided into experimental units/plots. Basal dose of fertilizer was applied during preparation of field. Top dressing of nitrogen was done at flowering initiation stage. Roguing, weeding and plant protection measures, were undertaken, when required.

\section{Observations recorded}

Data were recorded for various crop phenological parameters (plant height, flag leaf area and days to maturity), floral traits (pollen fertility and spikelet fertility), yield parameters (number of tillers per plant, 1000-grain weight and seed yield), canopy temperature depression at flag leaf stage $\left(\mathrm{CTD}_{1}\right)$ and at grain filling stage $\left(\mathrm{CTD}_{2}\right)$ and seed quality parameters (germination, Vigour index I and Vigour index II). Seed germination was determined as per ISTA (2008). Seedling vigour was calculated following formula suggested by Abdul-Baki and Anderson (1973) as Vigour Index $\mathrm{I}=$ Germination $\% \mathrm{x}$ Seedling length $(\mathrm{cm})$ and Vigour Index II $=$ Germination $\%$ x Seedling dry weight $(\mathrm{g})$. Canopy temperature (degree centigrade) was observed between 1300-1500hrs with an infrared thermometer pointed at the sunlit leaves from the top of canopy and interference by the exposed ground surface was avoided. Canopy temperature depression was estimated as difference of canopy temperature from mean air temperature.

The meteorological data regarding average rain fall $(\mathrm{mm})$, monthly minimum and maximum temperature were obtained from Division of Agricultural Physics, ICAR-IARI, New Delhi. Heat susceptibility index was calculated according to Fischer and Maurer (1978). In addition, heat susceptibility (per cent) was worked out as reduction in genotypic mean under stress environment from that of under non-stress environment and expressed as percent of mean of non-stress environment.

\section{RESULTS AND DISCUSSION}

Heat tolerance is a complex trait which has to be measured in terms of its manifestation towards changing the performance of a genotype for a given trait. Knowing the fact that stress accelerates the phenological development of the plant, thereby affecting all plant characters, it becomes imperative to study the comparative changes experienced in heat stress vs. non-stress environment (Kaur et al, 2007). Therefore planting the test material with two dates of sowing i.e. normal sown and late sown could very well serve this purpose as the normal sown crop is marginally exposed to terminal heat stress whereas late sown crop is exposed to significant higher temperatures during grain filling for a considerably long period. The yearly climatic fluctuations can render the conclusions invalid in other seasons. Therefore, the present study was conducted over two years and the genotypes were evaluated under both timely and late sown conditions in both the years. Fig. 1 represents theaverage meteorological data of two years regarding maximum and minimum temperature recorded at sowing, anthesis and maturity under both normal and heat stress environments. The average minimum and maximum monthly temperatures were approximately in the same range in both the cropping seasons. At post-anthesis stage (maturity), under normal condition, the temperature ranged from a minimum of $18^{\circ} \mathrm{Cupto}$ a maximum of $30^{\circ} \mathrm{C}$; whereas under heat stress condition, minimum temperature recorded was $22^{\circ} \mathrm{C}$ and maximum $40^{\circ} \mathrm{C}$. As a result, the material sown under late condition $\left(\mathrm{E}_{2}\right)$ experienced substantially higher temperature regimes from booting stage right upto the maturity as depicted in the figure.

\section{Effect of high temperature on phenological and floral traits}

The main factor behind crop development is the temperature along with photoperiod. The optimum temperature requirement for normal development of wheat plant for fertilization is $18^{\circ} \mathrm{C}$ to $24^{\circ} \mathrm{C}$; the minimum is $10^{\circ} \mathrm{C}$ and maximum is $32^{\circ} \mathrm{C}$. The severity of the possible damage to crop is determined by the developmental stage at which the plant is exposed to high temperature (Wahid et al., 2007). Plant height of all wheat genotypes was significantly reduced from $93.7 \mathrm{~cm}$ under normal sown condition to $58.3 \mathrm{~cm}$ under late sown condition (Table 1). Reduction in plant height of wheat genotypes due to late sowing and high temperature stress is also reported by Irfaq et al (2005). Flag leaves are the chief photosynthetic organs in wheat and play an important role in yield increase under varying environments. Flag leaf is desirable because it has lower water potential and turgor pressure but produces maximum photosynthesis and thus more dry matter production than lower leaves of the plant. The present study revealed that flag leaf area was also significantly reduced under late sown condition (heat stress environment). Leaf senescence was enhanced by higher temperature, which caused reduction in green leaf area, thereby resulting in drastic reduction in leaf area at later stage under heat stress. Flag leaf area of HD 2985 was maximum $\left(41.4 \mathrm{~cm}^{2}\right)$ under normal sown condition 


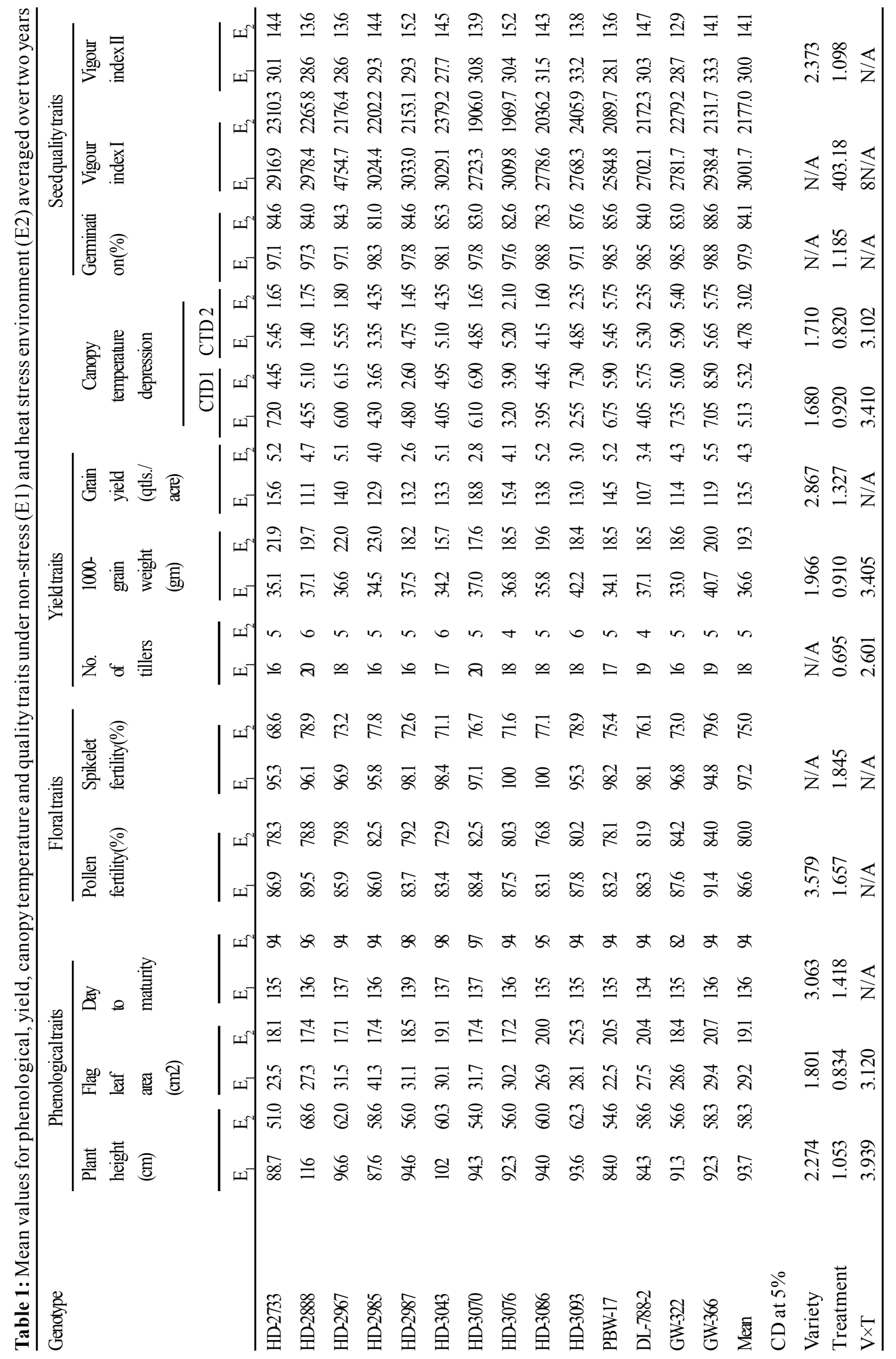




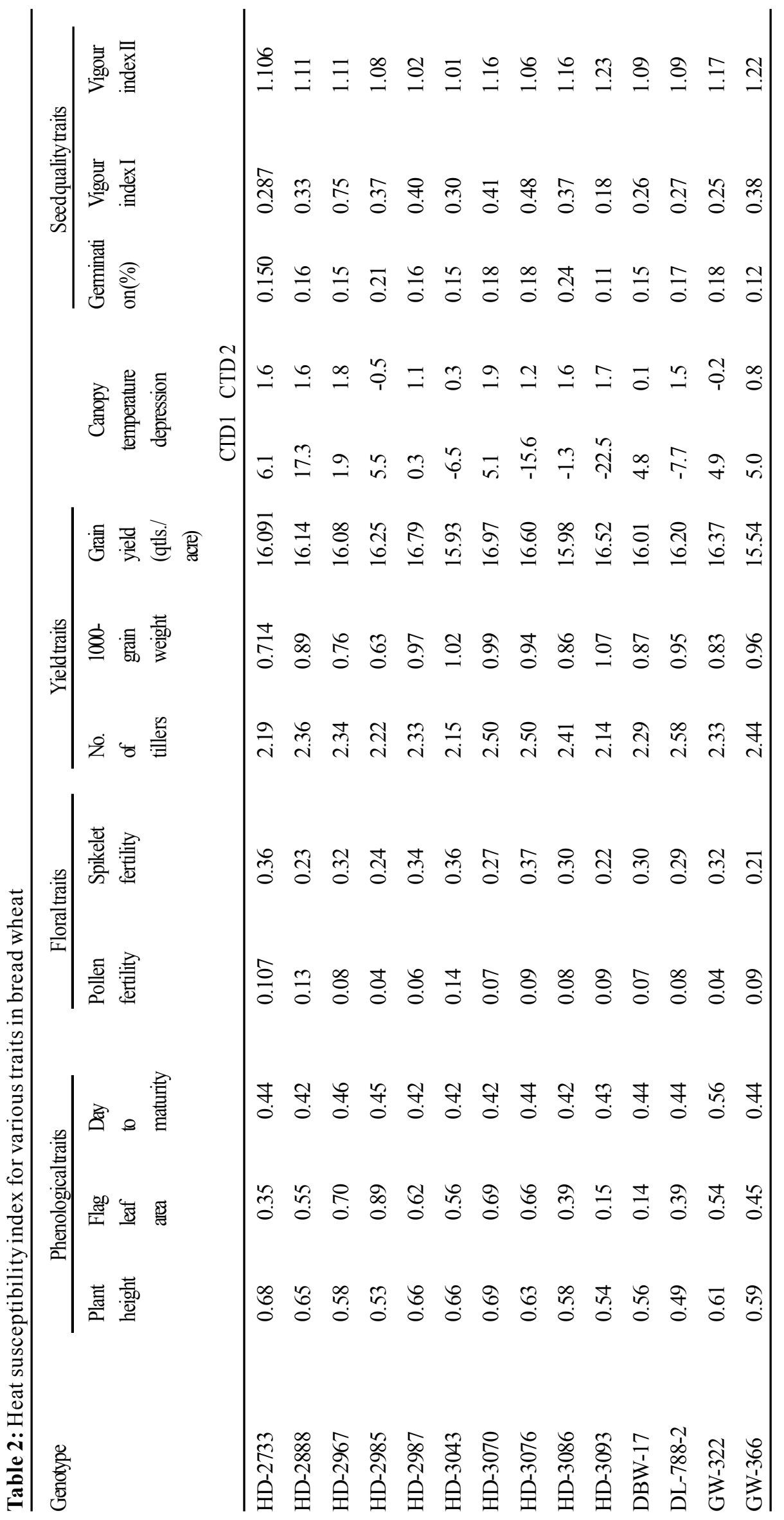




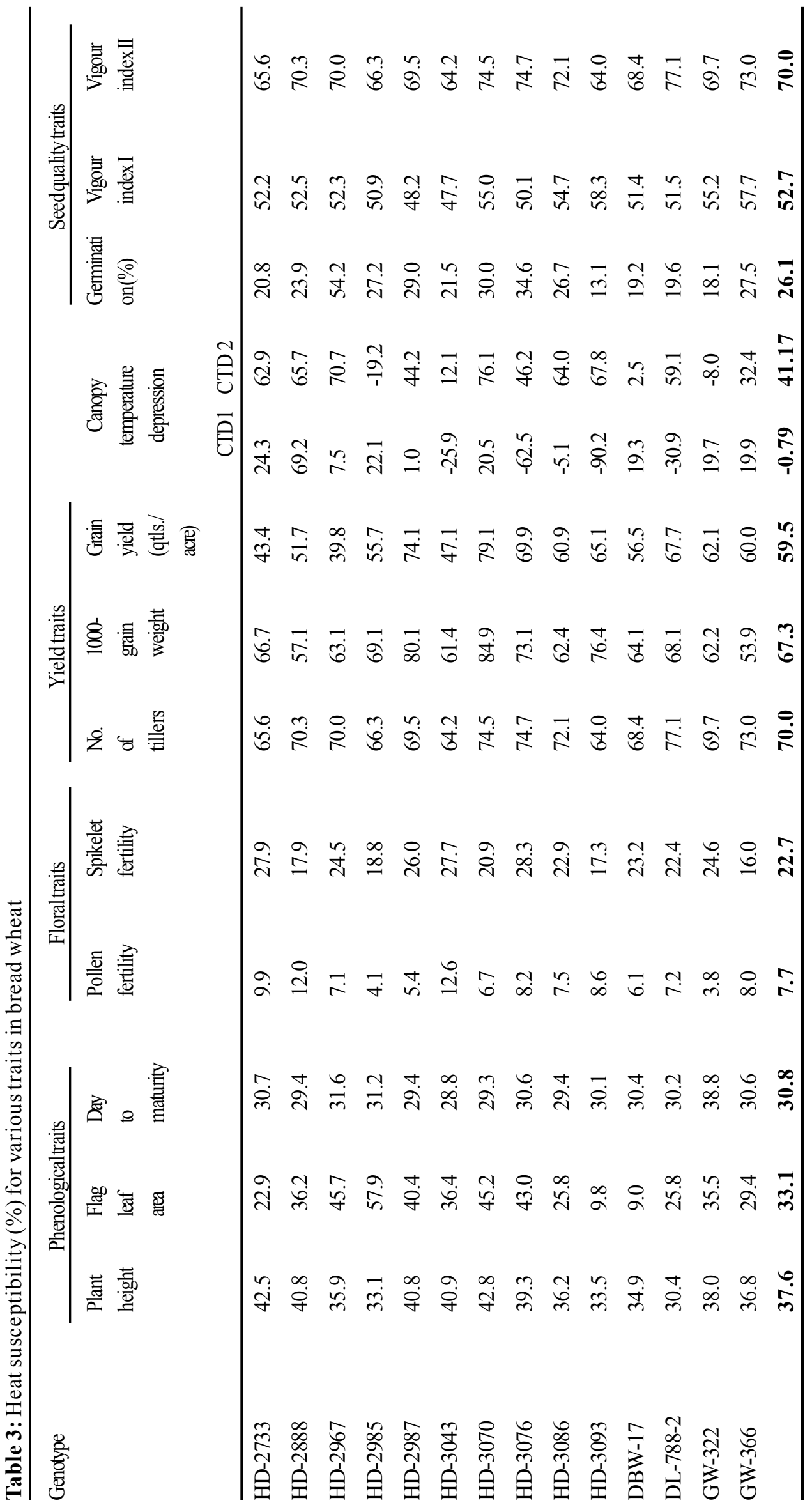



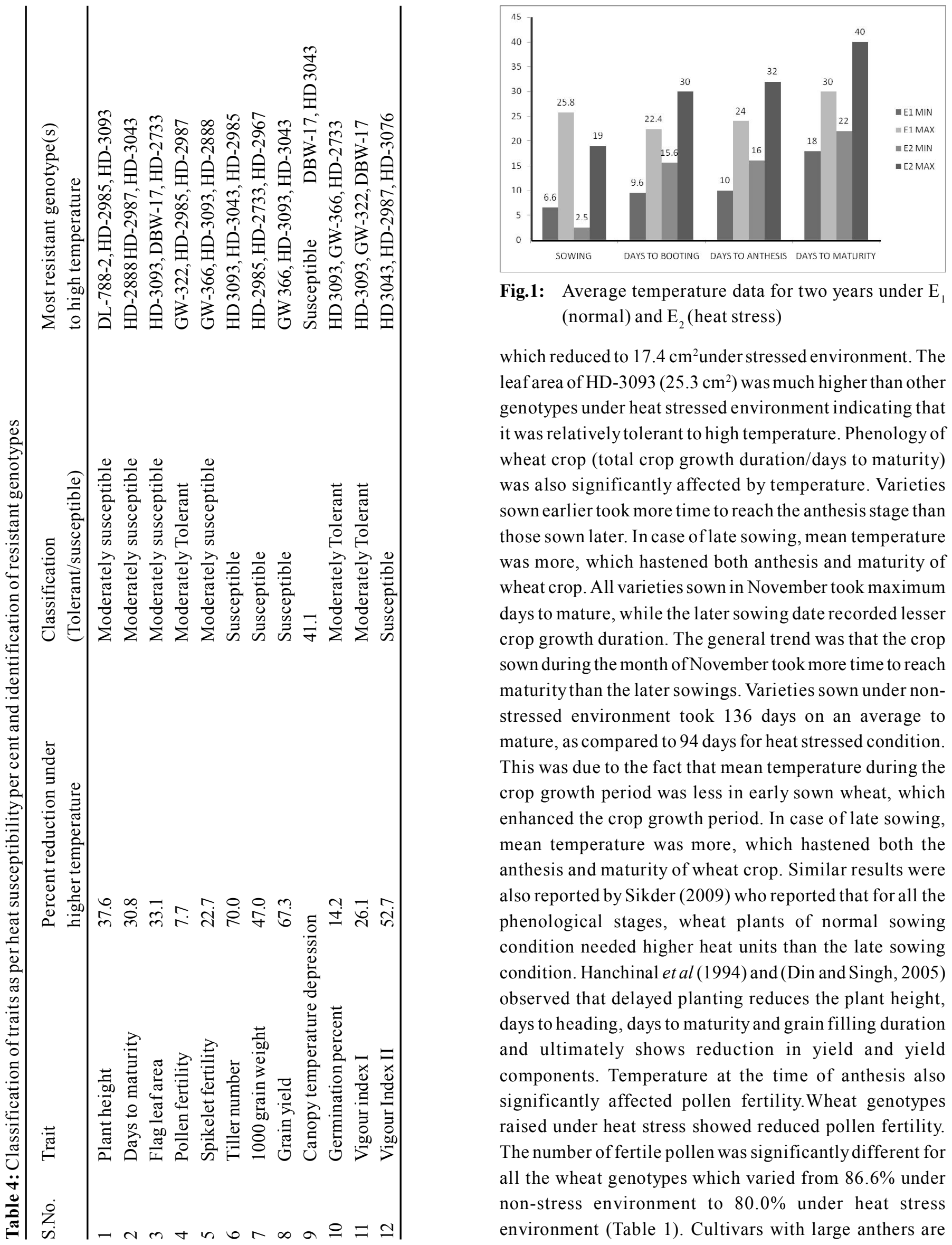

Fig.1: Average temperature data for two years under $\mathrm{E}_{1}$ (normal) and $\mathrm{E}_{2}$ (heat stress)

which reduced to $17.4 \mathrm{~cm}^{2}$ under stressed environment. The leaf area of HD-3093 $\left(25.3 \mathrm{~cm}^{2}\right)$ was much higher than other genotypes under heat stressed environment indicating that it was relatively tolerant to high temperature. Phenology of wheat crop (total crop growth duration/days to maturity) was also significantly affected by temperature. Varieties sown earlier took more time to reach the anthesis stage than those sown later. In case of late sowing, mean temperature was more, which hastened both anthesis and maturity of wheat crop. All varieties sown in November took maximum days to mature, while the later sowing date recorded lesser crop growth duration. The general trend was that the crop sown during the month of November took more time to reach maturity than the later sowings. Varieties sown under nonstressed environment took 136 days on an average to mature, as compared to 94 days for heat stressed condition. This was due to the fact that mean temperature during the crop growth period was less in early sown wheat, which enhanced the crop growth period. In case of late sowing, mean temperature was more, which hastened both the anthesis and maturity of wheat crop. Similar results were also reported by Sikder (2009) who reported that for all the phenological stages, wheat plants of normal sowing condition needed higher heat units than the late sowing condition. Hanchinal et al (1994) and (Din and Singh, 2005) observed that delayed planting reduces the plant height, days to heading, days to maturity and grain filling duration and ultimately shows reduction in yield and yield components. Temperature at the time of anthesis also significantly affected pollen fertility. Wheat genotypes raised under heat stress showed reduced pollen fertility. The number of fertile pollen was significantly different for all the wheat genotypes which varied from $86.6 \%$ under non-stress environment to $80.0 \%$ under heat stress environment (Table 1). Cultivars with large anthers are 
reported to be tolerant under high temperature stress at flowering stage (Matsui and Omasa, 2002). As the reduction in number of pollen grains that germinate on the stigma is directly related to temperature stress it can be assumed that that the tolerance to heat stress of cultivars with large anthers is due to large number of pollen grains per anther that compensates for reduction in number of pollen grains per anther. There was also significant difference in percentage seed set in the genotypes across the two different environments. The spikelet fertilitythus reduced from $97.2 \%$ under normal sown condition to $75 \%$ under high temperature. It has been earlier reported that heat stress during reproductive phase increases floret abortion (Wardlaw and Wrigley, 1994). However, temperatures above $30^{\circ} \mathrm{C}$, during floret formation, may cause complete sterility.

\section{Effect of high temperature on seed yield and quality parameters}

The major threat of terminal heat stress is during anthesis and grain filling period, which accelerates maturity and significantly reduces grain size, weight and yield. High temperature results in premature plant senescence and shortening of the period of photosynthetic activity (Ahmad et al., 2010). An approximate of 18 tillers per plant was recorded under normal sown condition as compared to only five tillers per plant under heat stress environment. Among the genotypes HD-2888 and HD-3070 recorded the highest number of tillers (20) under $E_{1}$ which decreased to a very minimal number of tillers ( 6 and 5 , respectively) under $\mathrm{E}_{2}$ (Table 1). A significant linear reduction was observed for 1000-grain weight of wheat genotypes with delay in sowing. On average basis, more 1000-grain weight (36.6g) was achieved under normal sowing which reduced drastically to $19.3 \mathrm{~g}$ under heat stress conditions. Four genotypes HD2985 (23.0 g), HD-2967 (22.0 g), HD 2733(21.9g) and GW 366 $(20.1 \mathrm{~g})$ had comparatively higher 1000 grain weight under higher temperature; hence showed more resistance to heat stress compared to others. Hence they were more heat tolerant genotypes as they showed more stability for this trait. Abdullah et al. (2007) reported that characters such as 1000-grain weight, test weight and flour yield declined progressively with delayed sowing. The loss in grain weight occursas a result of the injury caused by high temperature during the grain development period. High temperatures, above $30^{\circ} \mathrm{C}$, affect final grain weight by reducing the duration of grain filling, due to the suppression of current photosynthesis and by inhibition of starch synthesis in the endosperm. The optimum temperature range for reaching maximum kernel weight is $15-18^{\circ} \mathrm{C}$; higher temperature reduce the duration of grain filling and this reduction is not balanced by the increase in rate of assimilates accumulation (Stone and Nicolas, 1995). Calderini et al (1999) and Wardlaw (2002) also observed that reduction in grain weight is caused by high temperature during pre and post anthesis under field condition. Grain yield of wheat genotypes was higher at normal sowing which decreased with delay in sowing time. Highest grain yield (13.57 quintal/acre) was recorded at early sowing whereas linear reduction in grain yield was recorded at late sowing (4.3 quintal/acre). Grain yield for normal sowing ranged between 10.7 quintal/acre for DL-788-2 to 18.8 quintal/acre for HD-3070. Heat stress produced the lowest grain yield in all the genotypes; and genotypes HD-2733, DBW-17, and GW-366 were comparatively better yielders (5.2, 5.2 and 5.5quintal/acre, respectively) than the others. Earlier studies have also reported that exposure to higher temperatures can significantly reduce grain yield (Kant et al., 2014; Moshatati et al, 2012 and Riaz-ud-Din et al, 2010; Tewolde et al., 2006). According to Hays et al (2007), stress occurring after anthesis often has detrimental effects on wheat grain yield by hastening maturity, triggering premature senescence, shortening grain filling duration and reducing net assimilates and 1000 kernel weight.

Seed quality is very sensitive to temperature during the seed filling period because of the fact that high temperature can differentially affect the various processes involved in seed filling and the chemical composition of the seeds may also be modified by increasing temperature. A significant decrease in germination percent was observed under heat stress environment i.e. from $97.9 \%$ to $84.1 \%$ (Table 1). Seed vigour index-I also showed significant decreasein all cultivars under heat stress. Maximum vigour was observed in case of HD 2967 which recorded 4754.7 under normal sown condition compared to 2176.4 under heat stress. Similarly, seed vigour index-II also reduced from an average of 30.0 under normal sown conditions compared to 14.1 under heat stress condition. Thus, seeds that were produced and harvested under high temperature conditions in the later sowings were low in germination and vigour as compared to those that were raised under normal sown conditions. This could be due to asynchronous maturity of the seeds under high temperature conditions which results in variability in developmental stage of each seed. In addition, higher temperature during seed maturation period deteriorates seed reserves and enzymes related to seed germination. Grass and Burris (1995) also reported that high 
temperature resulted in low values of both seed yield and physical traits of seed quality in wheat.

\section{Heat susceptibility index}

The performance of wheat genotypes was observed to vary substantially over the two environments viz., nonstress and heat stress environments. The reduction in performance when sown under heat stress conditions from that of non-stress environment was calculated and expressed in the form of heat susceptibility index ('s' values) as in Table 2. The comparison of these values between normal versus late sown condition was used to identify genotypes which reflected resistant or susceptible genotypes for each trait.For plant height, DL-788-2(0.49), HD-2985(0.53) and HD-3093 (0.54) had least susceptibility to heat stress under heat stress condition and were thus identified as most resistant genotypes for this trait. Whereas genotypes HD3070 (0.69) and HD-2733 (0.68) showed higher heat susceptibility index, and were hence classified as susceptible. For flag leaf area, HD-3093(0.15) and DBW-17 (0.14) showed least susceptibility index compared to HD2985(0.89) and HD-2967(0.70). For days to maturity, HD2888 (0.41) had least susceptibility index compared to the other genotypes. Hence, it was identified as the most resistant genotype for this trait since it was least affected due to high temperature. The pollen fertility was also affected by heat stress wherein HD-2985 (0.4) and GW-322 (0.4) showed least susceptibility but HD-3043(0.14), HD-2888 (0.13) showed higher HSI. For spikelet fertility, GW-366 (0.21) and DBW-17(0.22) had least susceptibility index whereas HD-3076(0.37) and HD-2733 (0.36) had higher HSI under heat stress condition. For tiller number, genotypes viz. HD-3093 (2.14) and HD-3043 (2.15) had least susceptibilityindex whereas DL-788-2 (2.58), HD-3076(2.50) and HD-3086 (2.50) showed highest susceptibility index, thereby indicating that they were more affected by heat stress compared to others (Table 2). For 1000-grain weight; the genotypes showed high heat susceptibility index values ranging from 0.63 to 1.07 for HD-2985 and HD-3093, respectively. For grain yield; GW-366 (1.69) and HD-2888 (1.79) showed least susceptibility index whereas genotypes HD-3070 (2.66), HD-2987 (2.51), HD-3093 (2.39) and HD3076 (2.29) showed higher heat susceptibility index, and were hence classified as susceptible genotypes. High temperature stress $\left(+3.0^{\circ} \mathrm{C}\right.$ seasonal mean and $+5.6^{\circ} \mathrm{C}$ during ripening growth phase) has been reported to reduce grain yield and yield contributing characters to varying extent among the cultivars. Shortening of the grain filling duration generally decreases yield by decreasing kernel weight (Tahir and Nakata, 2005). For canopy temperature depression $\left(\mathrm{CTD}_{1}\right)$, 's' value was least for HD 2987 (0.3). The negative value of ' $s$ ' in most of the genotypes indicated more canopy temperature depression in late sown conditions. For $\mathrm{CTD}_{2}$, DBW 17 (0.1) and HD 3043 (0.3) had minimum heat stress intensity. For the germination percentage; HD-3093 (0.11) and GW-366 (0.12) had least susceptibility index whereas the genotypes HD-3086 (0.24) and HD-2985(0.21) had high susceptibility index. For the vigour index I; GW-322 (-0.25), HD-3093(0.18), and DBW-17 (0.26) had least susceptibility index whereas the genotypes HD-2967 (0.75), HD-3076 (0.48) and HD-3070 (041) had higher susceptibility index. For the vigour index II, HD-3043 (1.01) had the least susceptibility index and HD-3093 (1.23) had high susceptibility index. Similar results have been reported by Modhe et al (2008).

\section{Heat susceptibility per cent}

Heat susceptibility index is used to compare different genotypes for their relative susceptibility to heat. However, it does not indicate the relative susceptibility of different characters to heat stress. Therefore, with the objective to identify traits that are least affected when exposed to high temperature, the heat susceptibility was expressed as percent reduction in the performance of a trait under heat stress from that under non-stress condition. The comparison of group means over all genotypes for heat susceptibility indicated that there was a maximum reduction of $70 \%$ for tiller number under heat stress conditions (Table 3). Plant height showed $37.6 \%$ reduction due to late sown conditions. Irfaq et al (2005) also reported reduction in plant height of wheat genotypes due to late sowing and high temperature stress.Days to maturityand flag leaf area showed a reduction of $30.8 \%$ and $33 \%$, respectively. Pollen fertility and spikelet fertility were reduced by $7.7 \%$ and $22.7 \%$, respectively. 1000 -grain weight showed $67.3 \%$ reduction when crop was raised under heat stress condition. Abdullah et al. (2007) reported that characters such as 1000-grain weight, test weight and flour yield declined progressively with delayed sowing. Heat susceptibility percentage was recorded to be $59.5 \%$ for grain yield. Heat stress caused a reduction of $41.1 \%$ for canopy temperature (at grain filling stage). Reynolds et al (1994) examined a number of physiological traits associated with spring wheat yield under hot irrigated conditions, like stomatal conductance and CTD, and reported that these were highly affected by heat stress. Similar results were also reported by Kumar et al (2013). Among the seed quality parameters, vigour index II showed maximum 
reduction by $70 \%$, thereby classifying it as a susceptible trait. Germination percentage and vigour index I showed $26 \%$ and $53 \%$ reduction under heat stress condition. The classification of various traits into susceptible or tolerant category is depicted in Table 4 . In addition based on the heat susceptibility per cent, the study also identified tolerant genotypes w.r.t. all traits under investigation. Thus, genotypes GW 366, HD 3093 and HD 2888 were better performers w.r.t. grain yield under heat stress conditions whereas for seed quality aspects, HD 3093 showed better tolerance compared to others. The genotypes thus identified on the basis of these criteria will be of immense use for further exploitation in the breeding programme.

\section{REFERENCES}

Abdul-Baki, A.A. and Anderson, J.D. (1973). Vigor determination in soybean seed by multiple criteria. Crop Sci., 13:630-633

Abdullah, M.,Aziz-Ur-Rehman,Ahmad, N. and Rasul, I. (2007). Planting time effect on grain and quality characteristics of wheat. Pak. J. Agri. Sci., 44 (2): 200-202.

Ahmad, M.S.A., M. Ashrafand Q. Ali. (2010). Soil salinityas a selection pressure is a key determinant for the evolution of salt tolerance in blue panicgrass (Panicumantidotale Retz.). Flora, 205:37-45.

Alward, R. D., Detling, J. K. and Milchunas, D. G. (1999). Grassland Vegetation Changes and Nocturnal Global Warming. Science, 283: 229-231.

Calderini, D.F., L.G. Abedelo, R. Savin and G.A. Slafer. (1999). Final grain weight in wheat as affected by short period of high temperatures during pre and post-anthesis under field conditions. Aust. J. Plant Physiol., 26: 452458.

Din, K. and Singh, R.M. (2005). Grain filling duration: An important trait in wheat improvement. SAICNewsletter, 15(4): 4-5.

Fischer, R.A. and Maurer, R. (1978). Drought resistance in spring wheat cultivars. 1. Grain yield responses. Aus. Agri.Res. 29: 897-907

Grass L. and Burris J.S. (1995). Effect of heat stress during seed development and maturation on wheat (Triticum durum) seed quality. I. Seed germination and seedling vigor. $\mathrm{Can}$. J. Plant Sci., 75(4): 821-829.

Hanchinal, R.R., J.P.Tandon and P.M. Salimath.(1994). Variation and adaptation of wheat varieties for heat tolerance in
PeninsularIndia. In: Wheat in heat-stressed environments: Irrigated, dry areas and Rice-Wheat farming Systems. (Eds.): D.A. Saunders and G.P.Hettel.CIMMYT, Mexico, D.F. pp. $175-183$.

Hays, D.B., Do, J.H., Mason, R.E., Morgan, G. and Finlayson, S.A. (2007). Heat stress induced ethylene production in developing wheat grains induces kernel abortion and increased mutation in a susceptible cultivar. Plant Sci., 172: 1113-1123.

Houghton, J. T. (2001). The scientific basis: contribution of working group I to the third assessment reportof the intergovernmental panel on climate change. Climate Change, Cambridge University Press, pp 525-582.

Irfaq, M., Muhammad, T., Amin, M. and Jabbar, A. (2005). Performance of yield and other agronomic characters on four wheat cultivars under natural heat stress. Inter $J$ Bot., 1:124-127.

Kant, S., Lamba, R.A.S., Arya, R.K. and Panwar, I.S. (2014). Effect of terminal heat stress on stability of yield and quality parameters in bread wheat in south-west Haryana. J. Wheat Res., 6(1): 64-73.

Kaur, A., Sohu, V.S. and Mavi, G.S. (2007)Genotypic variation for physiological traits associated with heat tolerance in bread wheat (Triticumaestivum L.). Crop Improv. 34 (2): 117-23.

Kumar, R.R, Sharma, S.K., Goswami, S., Singh, G.P., Singh, R., Singh, K., Pathak, H. andRai, R.D.(2013)Characterization of differentially expressed stress-associated proteins in starch granule development under heat stress in wheat (TriticumaestivumL.). Indian J.Biochem Biophys., 50(2):126-138

Matsui, T. and Omasa, K.(2002) Rice(Oryza sativa L.) cultivars tolerant to high temperature at flowering: anther characteristics. Annals Bot., 89: 683-687.

Modhe, A., Naderi, A., Emam, Y., Aynehband, A., \&Normohamadi, G. (2008). Effects of post-anthesis heat stress and nitrogen levels on grain yield in wheat ( $\mathrm{T}$. durum and T. aestivum) genotypes. Int. J. Plant Prod., 2:257-268

Moshatati,A., Siadat, S.A., Saeid. K., Bakhshandeh,A.M. and Jalal, M.R. (2012). Effect of terminal heat stress on yield and yield components of spring bread wheat cultivars in Ahwaz, Iran. Intern. Agri.., 2: 844-49

Reynolds, M.P., Balota,M., Delgdo, M.I.B., Amani I. and 
Fischer, R.A. (1994). Physiological and morphological traits associated with spring wheat yield under hot, irrigated conditions. Australian J. Plant Physiol., 21: $717-30$

Riaz-Ud-Din, Subhani, G.M., Ahmad, N. ,Hussain, M and Rehman,A.(2010). Effect of temperature on development and grain formation in spring wheat. Pak.J. Bot., 42: 899906.

Sikder, S. (2009). Accumulated Heat Unit and Phenology of Wheat Cultivars as Influenced by Late Sowing Heat Stress Condition. JAgric Rural Dev., 7(1\&2), 57-64.

Stone, P.J. and Nicolas, M.E. (1995). A survey on the effects of high temperature during grain filling on yield and quality of 75 wheat cultivars. Aust.J.Agric. Res., 46:475-492.

Tahir, I. S.A., and Nakata, N. (2005). Remobilization of nitrogen and carbohydrate from stems of bread wheat in response to heat stress during grain filling. J. Agron. Crop Sci., 191: 106-115.
Tewolde, H., Fernandez, C. J., and Erickson, C.A. (2006). Wheat cultivars adapted to post-heading high temperature stress. J. Agron. Crop Sci., 192: 111-120.

Wahid A, Gelani S, Ashraf M, Foolad MR. (2007). Heat tolerance in plants: an overview. Envi.Experi. Bot., 61:199-223.

Wardlaw, I. F., and Wrigley, C. W. (1994). Heat tolerance in temperate cereals: an overview. Aust. J. Plant Physiol., 21:695-703.

Wardlaw, I.F. (2002). Interaction between drought and chronic high temperature during kernel filling in wheat in a controlled environment. Ann. Bot., 90(4): 469-476.

Zahedi, M., and Jenner, C. F. (2003). Analysis of effects in wheat of high temperature on grain filling attributes estimated from mathematical models of grain 1310 filling. J. Agric. Sci., 141:203-212. 